\title{
Article \\ The Tribotechnical Properties of Electrosparks with a Secondary Bronze Coating
}

\author{
Alexey Semyonovich Dorokhov, Vyacheslav Alexandrovich Denisov, Roman Nikolayevich Zadorozhny, \\ Ilya Vladimirovich Romanov *il and Vitaliy Aleksandrovitch Zuevskiy
}

Citation: Dorokhov, A.S.; Denisov, V.A.; Zadorozhny, R.N.; Romanov, I.V.; Zuevskiy, V.A. The Tribotechnical Properties of Electrosparks with a Secondary Bronze Coating. Coatings 2022, 12, 312. https://doi.org/10.3390/ coatings12030312

Academic Editor: Annalisa Fortini

Received: 24 November 2021

Accepted: 22 February 2022

Published: 25 February 2022

Publisher's Note: MDPI stays neutral with regard to jurisdictional claims in published maps and institutional affiliations.

Copyright: (C) 2022 by the authors. Licensee MDPI, Basel, Switzerland. This article is an open access article distributed under the terms and conditions of the Creative Commons Attribution (CC BY) license (https:// creativecommons.org/licenses/by/ $4.0 /)$.
Federal State Budget Scientific Institution (Federal Scientific Agricultural Engineering Center VIM), 1st Institute Travel, House 5, 109428 Moscow, Russia; dorokhov@rgau-msha.ru (A.S.D.); va.denisov@mail.ru (V.A.D.); warrior-saint@yandex.ru (R.N.Z.); zuevit1@mail.ru (V.A.Z.)

* Correspondence: gosniti1953@mail.ru

\begin{abstract}
The high cost of metal powder materials and the energy consumption of the methods involved in their production have led to an increase in the cost of technologies for the restoration and hardening of parts. One method of solving this problem is the recycling of powders. A promising method for processing the waste from machine-building industries, including those utilizing non-ferrous metals and alloys, is electroerosive dispersion. Metallic powders from secondary raw materials obtained in this manner have good physical and mechanical properties, and their cost is two to three times less than the cost of industrial ones. However, the tribotechnical properties of the secondary powders of non-ferrous metals and their use in technologies for the restoration and hardening of parts are still poorly understood. This paper presents a comparative analysis of the tribotechnical properties of coatings obtained via an electric spark treatment with electrodes composed of bronze $\mathrm{CuAl} 9 \mathrm{Fe} 3(\mathrm{CuAl} 8 \mathrm{Fe} 3$ ) (in the state of delivery), and coatings of sintered secondary bronze obtained via the method of electroerosive dispersion followed by spark plasma sintering. The results of the comparative tribotechnical tests under the conditions of dry friction showed that the complex indicator of wear resistance - the wear factor $(F)$ - under dry friction conditions, for mates after an electrospark coating method with sintered secondary bronze, was 1.94 less than for mates with a CuAl9Fe3 (CuAl8Fe3) coating. This confirmed the high tribotechnical properties and the effectiveness of using cheap secondary bronze in repair production in technologies for restoring and strengthening worn parts of machines operating under dry friction conditions.
\end{abstract}

Keywords: electroerosive dispersion; electrospark treatment; secondary bronze coating; testing; wear resistance

\section{Introduction}

During operation, parts become worn. This results in larger gaps in the joints and the subsequent failure of the assembly units. The extension of their service life is achieved either by replacing the worn part with a new component (spare part) or by restoring the functionality of said part via coating methods. The cost of spare parts is constantly increasing [1-3]; therefore, the restoration of worn-out parts with another resource to the level of a new part is one of the most efficient methods of saving money and material resources.

Many parts of agricultural machinery and equipment are composed of expensive non-ferrous metals and alloys. For example, a type T-170 tractor use up to 35 bronze bushings that have notable antifriction properties, corrosion resistance, high specific loads, and high-speed modes [4]. During operation, these parts are subject to intense wear, and require either replacement with new parts or restoration, usually using expensive powder or electrode materials composed of non-ferrous metals or alloys. The cost of tin and copper (the initial components of bronze) in the last three years on the world market has increased by $99.8 \%$ and $66.5 \%$, respectively $[5,6]$. In addition to the high cost of non-ferrous metals and alloys, the energy cost of producing powder materials from them constrains 
the diffusion of technologies for the reduction and reinforcement of such parts in repair production [7]. One method of solving this problem is the recycling of non-ferrous metals and alloys.

Electroerosive dispersion (EED) is a promising method used to process waste from machine-building processes, including non-ferrous metals and alloys [8]. The metallic powders from secondary raw materials produced by this method exhibit superior physical and mechanical properties, and their cost is two to three times less than the industrial value [9]. The wide use of secondary powders in repair manufacturing is achieved by briquetting and sintering. Electrodes are also produced from these powders; these can be used in different electric arc methods for applying coatings, including the application of the electrospark coating method (ES) [10], which is considered in this study. The choice of the electrospark coating method during our research was because of its versatility, costeffectiveness, and wide use in repair production, as well as the possibility of using only one piece of equipment for both the EED process and for the coating.

It should be noted that the tribomechanical properties of secondary powdered colored materials, as well as of electrode materials when used in the technologies of the reduction and hardening of parts, have not often been studied. Therefore, the study of the tribotechnical properties of electrospark bronze coatings formed from secondary colored alloys is a topical task.

A comparative analysis was undertaken of the tribotechnical conjugation properties of the coatings produced by ES electrodes from $\mathrm{CuAl} 19 \mathrm{Fe} 3(\mathrm{CuAl} 8 \mathrm{Fe} 3)$, and of the coatings from boiled secondary bronze obtained by electroerosive dispersion followed by spark plasma sintering (hereafter referred to as SPS bronze).

The objectives of this study were as follows:

- The production of an experimental batch of secondary bronze powder from the waste of machine-building production using the method of electroerosive dispersion;

- The production of a dispersed secondary bronze powder briquette at the SPS 10-3 spark plasma sintering plant of Thermal Technology (USA), to be cut into electrodes for ES prototype samples;

- The application of electrospark coatings to prototype sample discs by electrodes from bronze of $\mathrm{CuAl} 9 \mathrm{Fe} 3$ (CuAl8Fe3), and of electrospark coatings with electrodes from the boiled secondary SPS bronze;

- A metallographic analysis of the electrospark coatings on the prototype discs;

- Comparative tests for the wear of conjugations with the coatings produced by NUE electrodes from bronze-branded $\mathrm{CuAl} 9 \mathrm{Fe} 3$ (CuAl8Fe3), and with the coatings of electrodes from SPS bronze.

\section{Materials and Methods}

A batch of dispersed bronze powder from waste obtained via electroerosive dispersion was prepared for the pilot studies [11]. This was subjected to spark plasma sintering until a dense secondary alloy briquette was created of 95\% CuAl9Fe3 (CuAl8Fe3) bronze and the remainder of M1 (Cu-ETP) copper and CuK3Mn1 bronze.

For the electroerosive dispersion of the bronze waste, an Elitron-52B pulse generator (GOSNITI, Moscow, Russia) and a glass reactor with electrodes were used. The main technical characteristics of the Elitron-52B pulse generator are presented in Table 1. The working fluid in the reactor was distilled water. The bronze powder particles were up to $0.071 \mathrm{~mm}$ after dispersion. Particles of a correct spherical or elliptical shape formed during the crystallization of the molten metal were prevalent in the dispersed powder [12]. 
Table 1. Technical characteristics of the Elitron-52B and Vestron AI-007 (GOSNITI, Moscow, Russia) electric spark generators.

\begin{tabular}{ccc}
\hline \multirow{2}{*}{ Name of the Parameters } & \multicolumn{2}{c}{ Electrical Spark Treatment Plants } \\
\cline { 2 - 3 } & Elitron-52B & Vestron AI-007 \\
\hline Power consumption, $\mathrm{kW}$ & 3.5 & 1.5 \\
Power grid voltage, V & 220 & 220 \\
Electrode vibration frequency, Hz & 100 & 250 \\
Pulse frequency, Hz & 100 & $100 ; 150 ; 300$ \\
Working current, A & $0.5-80$ & $7.0-15$ \\
Number of electric modes, pieces & 12 & 24 \\
Overall dimensions of the generator, $\mathrm{mm}$ & $650 \times 600 \times 1100$ & $425 \times 415 \times 190$ \\
Generator mass, kg & 150 & 32 \\
\hline
\end{tabular}

The dispersed powder also had irregular particles up to 10 times smaller than those mentioned above, and which formed agglomerates with one another or with larger particles (Figure 1).

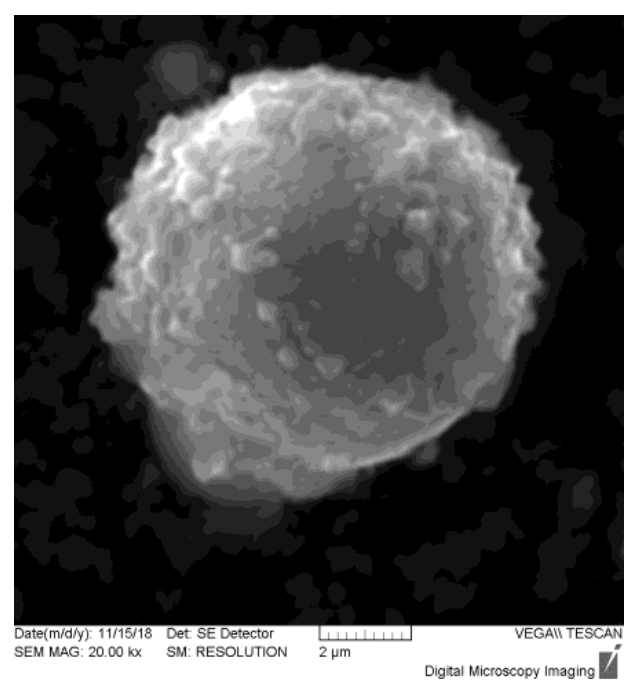

Figure 1. Shape of bronze powder particles. EED in distilled water $\times 20,000$.

The morphology and shape of the microparticles were determined using a TESCAN VEGA II (TESCAN, Brno, Czech Republic) raster electron microscope with an X-ray spectral analysis system INCA Energy 350 (Oxford Instruments Analytical, London, UK).

After the electroerosive dispersion of the scrap, the resulting powder was subjected to spark plasma sintering in order to obtain a dense briquette of the secondary alloy. The process of sintering the secondary bronze powder and producing the dense briquetted material was performed via the installation of an SPS 10-3 spark plasma sintering plant by Thermal Technology (Santa Rosa, CA, USA), at a temperature of $910^{\circ} \mathrm{C}$ for $5 \mathrm{~min}$ and under a vacuum of $40 \mathrm{MPa}$. The cooling rate was $100^{\circ} \mathrm{C} / \mathrm{min}$. At the same time as cooling, the pressure was dropped to $5 \mathrm{MPa}$ at a rate of $15 \mathrm{MPa} / \mathrm{min}$ [13]. After sintering, the bronze briquette was cut into electrodes for an electric spark treatment of $6 \times 6 \times 30 \mathrm{~mm}$.

The chemical composition of the electrode materials under investigation was determined using a Niton XL3t GOLD X-ray (CCS Services, Lausanne, Switzerland) fluorescence spectrometer (Table 2). 
Table 2. Chemical composition of the electrodes.

\begin{tabular}{cccccc}
\hline \multirow{2}{*}{ Electrode } & \multicolumn{5}{c}{ Elements, $\%$} \\
\cline { 2 - 6 } & $\mathbf{A l}$ & $\mathbf{S i}$ & $\mathbf{T i}$ & $\mathbf{M n}$ & $\mathbf{F e}$ \\
\hline CuAl9Fe3 & $6.94 \pm 0.38$ & $0.31 \pm 0.07$ & - & - & $1.68 \pm 0.01$ \\
SPS bronze & $4.42 \pm 0.30$ & $0.35 \pm 0.057$ & $0.11 \pm 0.01$ & $0.13 \pm 0.01$ & $1.41 \pm 0.01$ \\
\hline Electrode & $\mathbf{S}$ & $\mathbf{C u}$ & $\mathbf{Z n}$ & $\mathbf{S n}$ & $\mathbf{P b}$ \\
\hline CuAl9Fe3 & $0.18 \pm 0.05$ & $90.64 \pm 0.39$ & - & - & - \\
SPS bronze & - & $82.57 \pm 0.27$ & $10.21 \pm 0.05$ & $0.13 \pm 0.01$ & $0.28 \pm 0.01$ \\
\hline
\end{tabular}

The area of the specific surface and the average pore size of the electrode samples examined were evaluated using the specific surface analyzer of an Autosorb-1 (Quantachrome Instruments, Boynton Beach, FL, USA) (Table 3).

Table 3. Specific surface and porosity of the electrode materials.

\begin{tabular}{cccc}
\hline Sample View & Specific Surface, $\mathbf{~ m}^{2} / \mathbf{g}$ & Volume of Pores, $\mathbf{~ m}^{\mathbf{3}} / \mathbf{g}$ & Pore Radius, $\mathbf{~}$ \\
\hline CuAl9Fe3 & 1.09 & $4.4 \times 10^{-10}$ & $14.2 \times 10^{-10}$ \\
SPS bronze & 0.72 & $4.0 \times 10^{-10}$ & $15.5 \times 10^{-10}$ \\
\hline
\end{tabular}

For a comparative study of the tribotechnical properties, four sample discs were prepared from steel $5140 \mathrm{H}, 50 \mathrm{~mm}$ in diameter and $5 \mathrm{~mm}$ thick, with an electrospark applied at the installation of the Vestron AI-007 (Table 1), with electrodes made from $\mathrm{CuAl9Fe} 3(\mathrm{CuAl} 8 \mathrm{Fe} 3)$ bronze (reference) and from secondary SPS bronze in the form of two $10 \mathrm{~mm}$ wide tracks. The electrospark treatment of the surface of the samples was chosen so as to ensure the maximum values of the parameters, namely, the mass transfer of the material, the thickness increase of the coating, and the speed of the transfer of the material [14,15] (Table 4).

Table 4. Electrospark treatment modes of steel disc samples with bronze electrodes of CuAl9Fe3 (CuAl8Fe3) and bronze SPS.

\begin{tabular}{ccccc}
\hline \multirow{2}{*}{ Electrode Material } & \multicolumn{4}{c}{ Parameters } \\
\cline { 2 - 5 } & $\mathbf{U}, \mathbf{B}$ & $\mathbf{C}, \boldsymbol{\mu F}$ & $\mathbf{F}, \mathbf{H z}$ & $\mathbf{I} \mathbf{F}, \mathbf{A}$ \\
\hline CuAl9Fe3 (CuAl8Fe3) & 210 & 240 & 100 & 12 \\
SPS bronze & 160 & 300 & 100 & 13 \\
\hline
\end{tabular}

After ES, the coatings on the test samples were treated with M40 sandpaper (GOST R 52381-2005: abrasive materials, grain content and grain composition of the grinding powders, and grain composition control) until a surface roughness of 1.6-3.2 Ra was reached, providing a subsequent normal burnishing of the test connections.

The microhardness measurement of the coatings was performed on an automated microsolid-form DuraScan-20 (EMCO-TEST Prüfmaschinen GmbH, Kuchl, Austria) with a load of $0.05 \mathrm{~kg}$ and an exposure of 10-15 s, in accordance with GOST 9450-76 (measurement of microhardness by pressing diamond tips).

The measurement of the microhardness of the electrode materials made from bronze CuAl9Fe3 (CuAl8Fe3) and SPS bronze was performed on a microsolid measure of PMT-3M (JSC "LOMO", St. Petersburg, Russia) with a load of $0.1 \mathrm{~kg}$ and a maturation of 10-15 s, in accordance with GOST 9450-76 (measurement of microhardness by pressing diamond tips).

Comparative tests of the wear resistance of the electrospark coatings of the electrodes made from $\mathrm{CuAl} 9 \mathrm{Fe} 3(\mathrm{CuAl} 8 \mathrm{Fe} 3)$ bronze (in the state of delivery) and from secondary SPS bronze were performed on a tribometer (TRB-S-DE, CSM Instruments, Peseux, Switzerland), in accordance with GOST 23.224-86 (ensuring the wear resistance of products and methods for ensuring the durability of repaired parts). 
The wear on the test samples and counter-samples was evaluated by weighing before and after the tests on an analytical balance (Acculab ALC-210d4, New York, NY, USA) (weighing limit $210 \mathrm{~g}$, discreteness $0.0001 \mathrm{~g}$, class I special), and then counted for linear wear [16].

The tests on the tribometer were performed according to a circular motion scheme, where the sample disk with the investigated coating was rotated at a given speed. On it was placed an indentor (counter-sample) in the form of a ball with a diameter of $6 \mathrm{~mm}$ composed of 100Cr6. The endurance of the investigated coatings was evaluated in conjunction with the counter-model $[17,18]$.

The characteristics of the working environment of the tests were recorded by the sensors of the tribometer (humidity: $45-50 \%$; ambient temperature: $23-25{ }^{\circ} \mathrm{C}$ ). The tests were carried out under the conditions of the boundary (M-10G2k motor oil according to GOST 8581-78 (motor oils for automotive diesel engines and technical conditions)) and dry friction with a relative sliding speed of $0.2 \mathrm{~m} / \mathrm{s}$.

The samples were burnished in the tribometer under a step-by-step increase in $P$. The results of these tests assessed the burnishability of the investigated interfaces as well as the optimal load with minimum friction coefficients, $P_{0}$, the maximum bonded interface load, $P_{m}$, and the maximum load of an unprocessed interface, $P_{u}$, for which the bonding index value was calculated (Table 5):

$$
B=\frac{P_{m}-P_{u}}{\mu_{o} \times P_{o}}
$$

Table 5. Microhardness of the test materials.

\begin{tabular}{cccccccccccccc}
\hline Material & \multicolumn{10}{c}{ Simultaneous Indicators for Vickers $\mathbf{H} \boldsymbol{\mu}(\mathbf{H V})$} & $\begin{array}{c}\text { Mean } \\
\text { Value }\end{array}$ \\
\hline $\begin{array}{c}\text { Electrode from SPS } \\
\text { bronze }\end{array}$ & 95 & 77 & 90 & 101 & 106 & 117 & 75 & 87 & 94 & 85 & 93 \\
\hline $\begin{array}{c}\text { Standard electrode } \\
(\mathrm{CuAl9Fe3})\end{array}$ & 151 & 166 & 176 & 155 & 164 & 165 & 160 & 177 & 213 & 178 & 171 \\
\hline
\end{tabular}

The coefficient of friction $\mu$ and the depth of the friction track $h$ were continuously recorded during the tests.

In the second stage, long endurance tests of the test interfaces were performed at their $P_{0}$ loads.

The material durability of the specimens was assessed using the average wear rate $J$ for the tested specimens, as determined by the following formula:

$$
J=\frac{W}{L}, \mathrm{~m} / \mathrm{m}
$$

where $W$ is the linear wear of the sample $(\mathrm{m})$ and $L$ is the friction path $(\mathrm{m})$.

In determining the linear wear, $W$ was weighted by the following formula:

$$
W=\frac{\Delta G}{\gamma \times S}
$$

where $\Delta G$ is the change in the mass of the test sample $(\mathrm{kg}), \gamma$ is the density of the worn material $\left(\mathrm{kg} / \mathrm{m}^{3}\right)$, and $S$ is the contour area of contact of the samples $\left(\mathrm{m}^{2}\right)$. The friction path $L$ of the sample corresponding with wear $W$ was:

$$
L=N \times l
$$

where $l$ is the linear surface of the friction of the conjugate sample in the sliding direction, $m$, and $N$ is the number of cycles for each of which the friction surfaces of a sample pass through $l$. 
The wear rate of the friction pair as a whole, the sample, and the counter-sample (or, for the tribometer test, the disc and ball) was defined as the sum of the wear rates of $J_{\Sigma}$ of the pair of elements.

The comparison of the wear rates was based on the deterioration factor $F$, as determined by the following formula:

$$
F=\frac{J_{\Sigma}}{P_{o}}, \mathrm{~m} / \mathrm{mN}
$$

\section{Results and Discussion}

A comparative analysis of the chemical composition (Table 1) and the area of the materials (Table 2) of the studied electrodes made from secondary SPS bronze after recycling and from $\mathrm{CuAl}$ Fe3 (CuAl8Fe3) bronze (in the state of delivery) did not show any significant differences, indicating the comparability (approximation) of the physical and mechanical properties of the materials under study. A slight discrepancy in the indicators was due to the possible presence of up to $5 \%$ impurities in the scrap metal waste (M1 (Cu-ETP) copper and CuK3Mn1 bronze), with which we modeled a small contamination of the secondary material.

A microstructural analysis of the electrode materials and electrospark coatings under investigation was performed on grids. Grinding was undertaken using the equipment of the Struers (Copenhagen, Denmark) training line (Labotom-3 Struers hand-held machine, CitoPress-1 Struers automatic electrohydraulic press, Labopol-5 Struers grinding and polishing machine), and then studied using an inverted metallographic microscope Olympus GX51 (Olympus Corporation, Tokyo, Japan).

A metallographic analysis of the electrode materials showed that the microstructure of the IPA bronze electrode (Figure 2) consisted of fine grains with a pronounced spherical shape, in contrast to the microstructure of $\mathrm{CuAl}$ Fe3 (CuAl8Fe3) bronze (Figure 3). This state of the electrode material was associated with the shape of the particles of the initial powder and the peculiarity of the process of its sintering [19].

A metallographic analysis of the electrospark coatings of the $\mathrm{CuAl}$-Fe3 (CuAl8Fe3) and SPS bronze electrodes showed that the coatings had a dense structure with slight faults in the form of shells (1) and microcracks (2) (Figures 4 and 5).

The average thickness of the coating on the test samples with the use of electrodes made from CuAl9Fe3 (CuAl8Fe3) was $375 \mu \mathrm{m}$, while that on those made from SPS bronze was $127 \mu \mathrm{m}$. The significant variation of the profile in the thickness of the CuAl9Fe3 ( $\mathrm{CuAl} 8 \mathrm{Fe} 3)$ coating required the alignment of its mechanical processing due to the characteristics of the coating formation for the given material, practically eliminating the advantage in thickness.

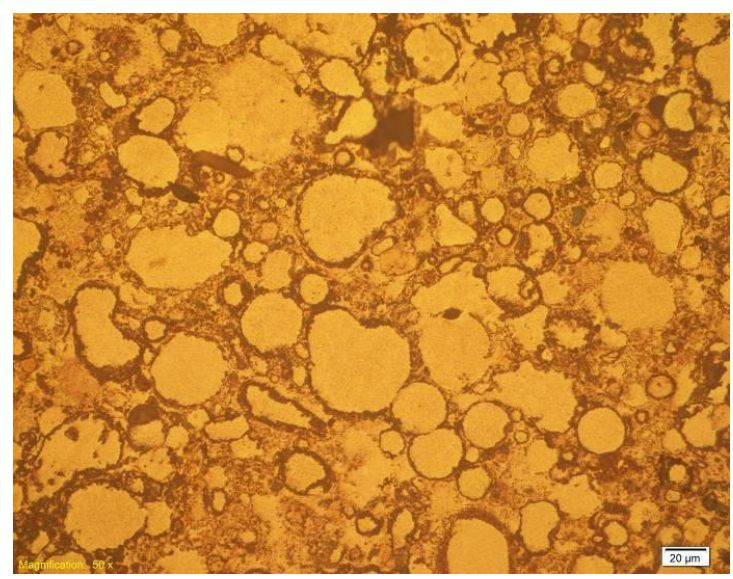

Figure 2. Microstructure of the forged SPS bronze $(\times 500)$. 


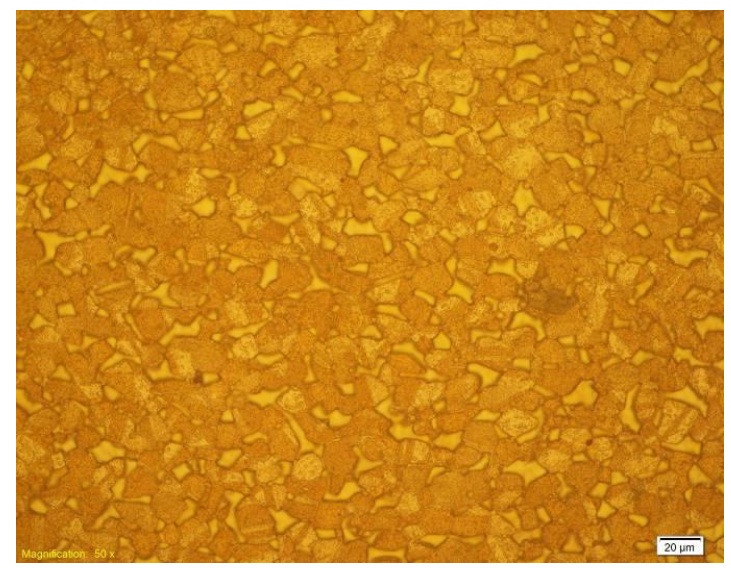

Figure 3. Bronze microstructure of CuAl9Fe3 $(\times 500)$.

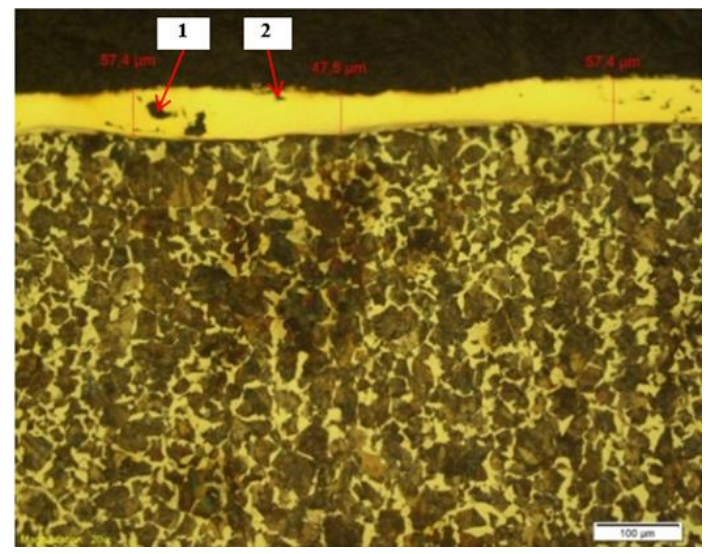

Figure 4. Microstructure of a sample with an electrospark coating of CuAl9Fe3 (CuAl8Fe3) (×200).

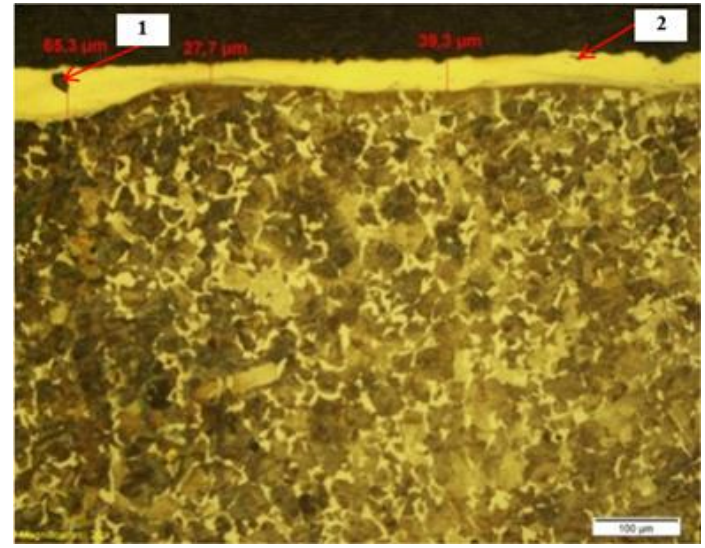

Figure 5. Microstructure of a sample with an electrospark coating of SPS bronze $(\times 200)$.

The microhardness of the surface, determined using a PMT-3M device, for the electric spark coatings with CuAl9Fe3 (CuAl8Fe3) bronze, was in the range of 190-230 HV; for the coatings of SPS bronze, it was 90-110 HV-1.8 times lower (Table 5).

The microhardness of the zone of thermal influence was determined using a DuraScan20 device. For the surface with bronze, this was $550 \mathrm{HV}$, while in the treatment with bronze it was $430 \mathrm{HV}$ - that is, 1.28 times lower (Figure 6). A slight decrease in the microhardness of the coatings with the SPS bronze electrodes in comparison with $\mathrm{CuAl}$ - Fe3 $(\mathrm{CuAl} 8 \mathrm{Fe} 3)$ bronze was explained by the lower microhardness of the electrode material, which could be increased by optimizing the modes of sintering and electric spark treatment with SPS bronze. 


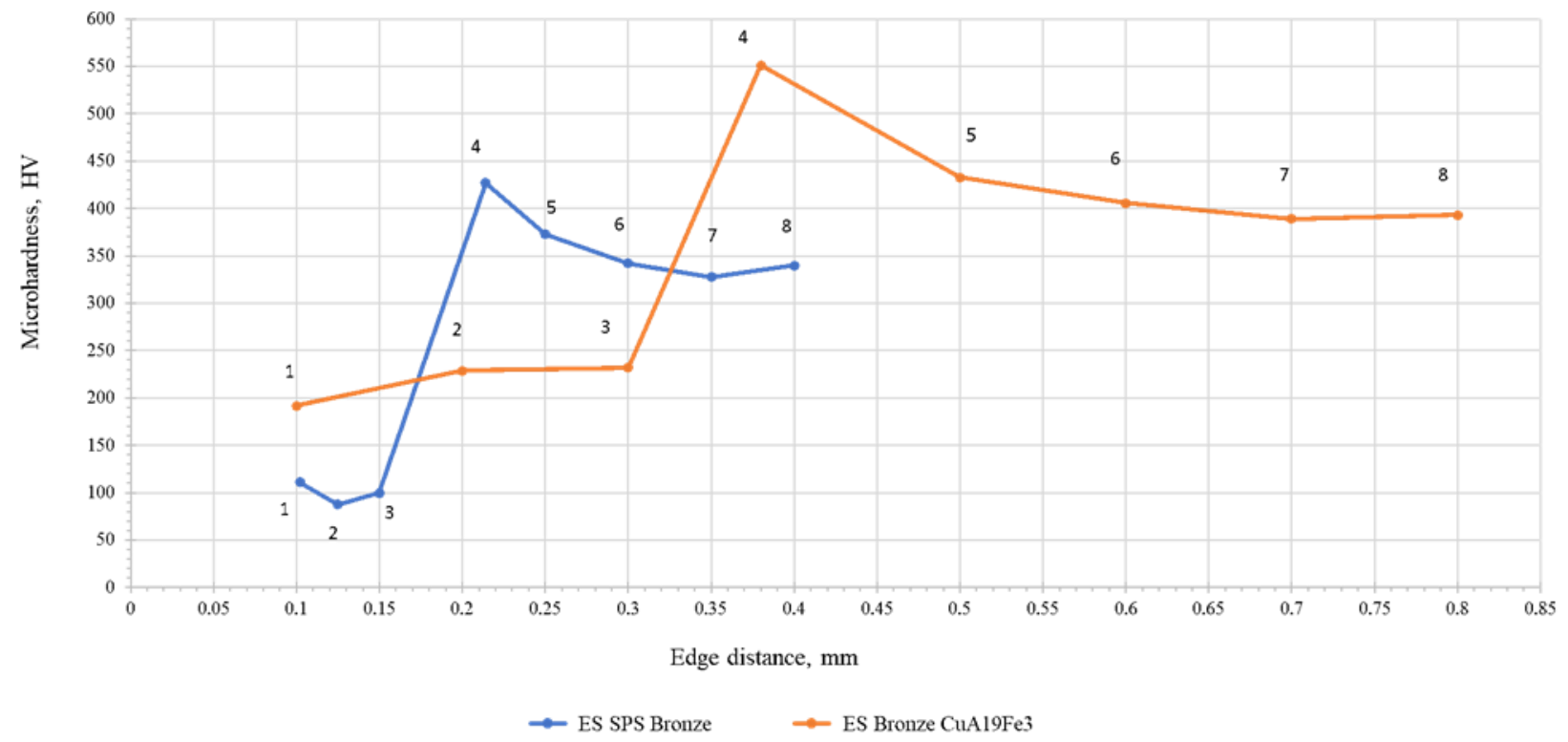

Figure 6. Distribution of microhardness by depth of coatings composed of CuAl9Fe3 bronze and SPS bronze. 1-3: coating; 4: thermal exposure zone; 5-8: base material.

The test results of the investigated couplings for the running-in performance (Table 6) showed that the couplings with SPS bronze in comparison with CuAl9Fe3 bronze under dry friction conditions had a running-in indicator $(B)$ that was 1.78 times higher; the maximum bearing capacity $\left(P_{m}\right)$ was 1.09 times higher. Under the conditions of boundary friction, mating with SPS bronze in comparison with $\mathrm{CuAl9Fe} 3$ bronze had a running-in rate $(B) 0.94$ times lower, and the maximum bearing capacity $\left(P_{m}\right)$ was 0.74 times lower. In comparison with $\mathrm{CuAl} 9 \mathrm{Fe} 3$ bronze, the running-in performance was superior, and was less prone to seizing when working under dry friction conditions. When operating under the conditions of boundary friction, the running-in indicator of the investigated interfaces with SPS bronze in comparison with $\mathrm{CuA19Fe} 3$ bronze was 0.94 times lower (which was comparable with

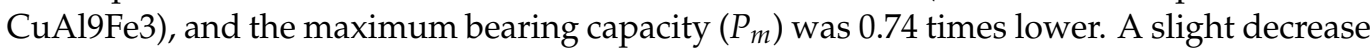
in the $P_{m}$ index indicated a tendency toward the jamming of mates with SPS bronze in comparison with $\mathrm{CuAl} 19 \mathrm{Fe} 3$ under boundary friction conditions.

Table 6. Assessment of the electrospark coating interface properties of tank-drive units of $\mathrm{CuAl} 9 \mathrm{Fe} 3$ and SPS bronze.

\begin{tabular}{|c|c|c|c|c|c|c|c|c|}
\hline \multirow{2}{*}{$\begin{array}{c}\text { No. of } \\
\text { Interfaces }\end{array}$} & \multirow{2}{*}{$\begin{array}{l}\text { Coating of the } \\
\text { Sample Disc }\end{array}$} & \multirow{2}{*}{$\begin{array}{c}\text { Counter-Sample } \\
\text { Material }\end{array}$} & \multirow{2}{*}{ Type of Friction } & \multirow{2}{*}{$\begin{array}{c}\text { Indicator of } \\
\text { Workability, B }\end{array}$} & \multicolumn{3}{|c|}{ Performance Indicators, $P$} & \multirow{2}{*}{$\begin{array}{c}\text { Factor of Friction in } \\
\text { Normal Mode, } \mu_{o}\end{array}$} \\
\hline & & & & & $P_{u}$ & $P_{o}$ & $P_{m}$ & \\
\hline 1.1 & ES CuA19Fe3 & Steel 100Cr6 & Dry & 1.02 & 5 & 5 & 9 & 0.784 \\
\hline 1.2 & ES CuA19Fe3 & Steel 100Cr6 & Dry & 1.28 & 5 & 5 & 15 & 1.561 \\
\hline 1.3 & ES CuA19Fe3 & Steel 100Cr6 & Dry & 2.27 & 7 & 3 & 11 & 0.588 \\
\hline 1.4 & ES CuA19Fe3 & Steel 100Cr6 & Dry & 1.02 & 5 & 5 & 9 & 0.784 \\
\hline 2.1 & ES SPS bronze & Steel 100Cr6 & Dry & 2.35 & 3 & 5 & 11 & 0.681 \\
\hline 2.2 & ES SPS bronze & Steel 100Cr6 & Dry & 1.91 & 7 & 3 & 13 & 1.045 \\
\hline 2.3 & ES SPS bronze & Steel 100Cr6 & Dry & 3.33 & 3 & 3 & 13 & 1.001 \\
\hline 2.4 & ES SPS bronze & Steel 100Cr6 & Dry & 2.35 & 3 & 5 & 11 & 0.681 \\
\hline 3.1 & ES CuA19Fe3 & Steel 100Cr6 & Boundary friction & 2.31 & 3 & 13 & 40 & 1.230 \\
\hline 3.2 & ES CuA19Fe3 & Steel 100Cr6 & Boundary friction & 0.42 & 5 & 25 & 40 & 3.364 \\
\hline 3.3 & ES CuA19Fe3 & Steel 100Cr6 & Boundary friction & 1.10 & 5 & 15 & 40 & 2.119 \\
\hline 3.4 & ES CuA19Fe3 & Steel 100Cr6 & Boundary friction & 3.21 & 5 & 9 & 40 & 1.213 \\
\hline 3.5 & ES CuA19Fe3 & Steel 100Cr6 & Boundary friction & 2.31 & 3 & 13 & 40 & 1.229 \\
\hline 4.1 & ES SPS bronze & Steel 100Cr6 & Boundary friction & 2.27 & 3 & 13 & 25 & 0.747 \\
\hline 4.2 & ES SPS bronze & Steel 100Cr6 & Boundary friction & 0.81 & 7 & 15 & 31 & 1.969 \\
\hline 4.3 & ES SPS bronze & Steel 100Cr6 & Boundary friction & 1.99 & 5 & 9 & 31 & 1.453 \\
\hline 4.4 & ES SPS bronze & Steel $100 \mathrm{Cr} 6$ & Boundary friction & 1.99 & 5 & 9 & 31 & 1.454 \\
\hline
\end{tabular}


Long-term tests of the wear resistance of the investigated mates at optimal loads $P_{o}$ corresponding with the minimum coefficient of friction $\mu_{0}$ in the steady-state friction mode of the running-in mate showed that the wear factor $(F)$ of the mates after ES of SPS with bronze when operating under dry friction conditions was 1.94 lower than that of the mates with the $\mathrm{CuAl} 9 \mathrm{Fe} 3$ coating; under conditions of boundary friction, this was 1.29 times higher (Table 7).

Table 7. The results of the test interfaces for durability.

\begin{tabular}{|c|c|c|c|c|c|c|c|c|}
\hline Interfaces & $P_{o}$ & $\begin{array}{l}\text { Factor of } \\
\text { Friction in } \\
\text { Normal } \\
\text { Mode, } \mu_{o}\end{array}$ & $\begin{array}{c}\text { Path of } \\
\text { Friction, m }\end{array}$ & $\begin{array}{c}\text { Linear Wear } \\
\text { of Sample } \\
\text { Disc } \\
\times 10^{-6} \mathrm{~m}\end{array}$ & $\begin{array}{l}\text { Linear Wear of } \\
\text { the Counter- } \\
\text { Sample, } \\
\times 10^{-6} \mathrm{~m}\end{array}$ & Type of Friction & $\begin{array}{l}\text { Intensity of } \\
\text { Wear and Tear, } \\
\times 10^{-13}, \mathrm{~m} / \mathrm{m}\end{array}$ & $\begin{array}{c}\text { Wear Factor } \\
F \times 10^{-14} \\
\mathrm{~m} / \mathrm{mN}\end{array}$ \\
\hline 1.1 & 5 & 0.784 & 5770 & 2.386 & 0.071 & Dry & 4.257 & 85.14 \\
\hline 1.2 & 5 & 1.561 & 4750 & 0.585 & 0.087 & Dry & 1.414 & 28.33 \\
\hline 1.3 & 3 & 0.588 & 5769 & 0.807 & 0.004 & Dry & 1.406 & 46.86 \\
\hline 1.4 & 5 & 0.784 & 5286 & 2.092 & 0.389 & Dry & 4.693 & 93.86 \\
\hline 2.1 & 5 & 0.681 & 6225 & 0.583 & 0.743 & Dry & 2.130 & 42.60 \\
\hline 2.2 & 3 & 1.245 & 5723 & 0.601 & 0.048 & Dry & 1.135 & 37.82 \\
\hline 2.3 & 3 & 1.001 & 5769 & 0.035 & 0.051 & Dry & 0.149 & 4.97 \\
\hline 2.4 & 5 & 0.681 & 6225 & 1.232 & 0.547 & Dry & 2.858 & 57.15 \\
\hline 3.1 & 13 & 1.230 & 5770 & 0.240 & 0.231 & Boundary friction & 0.815 & 6.29 \\
\hline 3.2 & 25 & 2.120 & 5769 & 0.089 & 0.100 & Boundary friction & 0.327 & 1.31 \\
\hline 3.3 & 15 & 2.120 & 5769 & 0.082 & 0.050 & Boundary friction & 0.229 & 1.52 \\
\hline 3.4 & 9 & 1.213 & 5769 & 0.053 & 0.097 & Boundary friction & 0.261 & 2.90 \\
\hline 3.5 & 13 & 1.230 & 5770 & 0.319 & 0.384 & Boundary friction & 1.220 & 9.38 \\
\hline 4.1 & 13 & 0.747 & 6225 & 0.160 & 0.538 & Boundary friction & 1.120 & 8.62 \\
\hline 4.2 & 15 & 1.969 & 5769 & 0.046 & 0.064 & Boundary friction & 0.191 & 1.27 \\
\hline 4.3 & 9 & 1.453 & 5769 & 0.244 & 0.032 & Boundary friction & 0.479 & 5.32 \\
\hline 4.4 & 9 & 1.452 & 5769 & 0.264 & 0.091 & Boundary friction & 0.616 & 6.84 \\
\hline
\end{tabular}

\section{Conclusions}

Our experimental studies demonstrated high indicators of the tribotechnical properties of electrospark coatings with electrodes composed of sintered secondary materials (SPS bronze) for mates operating under dry friction conditions. These were not inferior to the spark coatings with $\mathrm{CuA19Fe} 3$ electrodes (in the state of delivery). The recycling of powder materials-including for sintering electrodes - using electroerosive dispersion opens up opportunities for obtaining new raw materials used in technologies for the restoration and hardening of parts of various pieces of equipment.

A slight increase in the complex indicator of the wear factor $(F)$ of mates after ES of SPS with bronze in comparison with mates with a $\mathrm{CuAl} 9 \mathrm{Fe} 3$ coating - that is, a deterioration of the tribotechnical properties tested under boundary friction conditions-was most likely associated with the choice of lubricant, the sintering modes of the powder materials, the ES modes, and the selection of the material of the counter-body. The solution to these issues can determine the direction of further experimental research.

Author Contributions: Conceptualization, A.S.D. and V.A.D.; methodology, R.N.Z.; software, I.V.R.; validation, A.S.D. and V.A.D.; formal analysis, I.V.R.; investigation, V.A.Z.; resources, R.N.Z.; data curation, V.A.D.; writing—original draft preparation, I.V.R. and V.A.Z.; writing—review and editing, V.A.D. and R.N.Z.; visualization, I.V.R.; supervision, R.N.Z.; project administration, V.A.D.; funding acquisition, A.S.D. All authors have read and agreed to the published version of the manuscript.

Funding: This research received no external funding.

Conflicts of Interest: The authors declare no conflict of interest.

\section{References}

1. Burumkulov, F.H.; Ivanov, V.I.; Velichko, S.A.; Denisov, V.A. Plasticity of electro-spark copper-containing coatings. Electron. Process. Mater. 2014, 50, 6-9.

2. Beilis, V.M.; Tsench, Y.S.; Korotchenya, V.M.; Starovoitov, S.I.; Kynev, N.G. Development trends of progressive machine technologies and techniques in agricultural production. Bull. VIESH 2018, 4, 150-156. 
3. Ignatov, V.I.; Dorokhov, A.S.; Gerasimov, V.S.; Denisov, V.A. Methodology for determining the value of the utilization fee for decommissioned self-propelled equipment. Eng. Technol. Syst. 2019, 29, 124-139. [CrossRef]

4. Biryukov, V.V. Restoration of bronze parts of agricultural machines. Proc. GOSNITI 2009, 103, 141-143.

5. Copper Price (LME.Copper) for the Last 3 Years. Available online: https://bhom.ru/commodities $/ \mathrm{med} /$ ?startdate=3years (accessed on 23 November 2021).

6. Tin Price (LME.Tin) for the Last 3 Years. Available online: https://bhom.ru/commodities/olovo/?startdate=3years (accessed on 23 November 2021).

7. LobachevskyYa, P.; Sidorov, S.A.; Mironov, D.A.; Khoroshenkov, V.K.; Vaynerman, A.E.; Pichuzhkin, S.A.; Golosienko, S.A.; Chernobaev, S.P.; Yurkov, M.A. New wear-resistant surfacing materials in agricultural engineering. Agric. Mach. Technol. 2014, 6, 27-31.

8. Latypov, R.A.; Ageev, E.V.; Denisov, V.A.; Latypova, G.R. Recycling of wastes of hard alloys for the restoration and hardening of products. Monogr. Kursk. 2017, 184.

9. Romanov, I.V.; Zadorozhny, R.N. Methods of obtaining metal powders for technologies of restoration and hardening of parts of agricultural machinery. Agric. Equip. Maint. Repair 2019, 11, 37-44.

10. Verkhoturov, A.D.; Ivanov, V.I.; Dorokhov, A.S.; Konevtsov, L.A.; Velichko, S.A. Influence of the nature of electrode materials on erosion and properties of the alloyed layer. Evaluation criteria for electrospark alloying. Bull. Mordovian Univ. 2018, 28, 302-320. [CrossRef]

11. Latypov, R.A.; Ageev, E.V.; Khardikov, S.V.; Denisov, V.A.; Altukhov, A. X-ray spectral microanalysis of sintered steel from powder obtained by electroerosive dispersion of steel waste ShKh15. Electrometallurgy 2017, 2, 37-40.

12. Romanov, I.V.; Zadorozhny, R.N. Isolation of a finely dispersed fraction of powders obtained by the method of electroerosive dispersion. Tech. Serv. Mach. 2020, 3, 119-127.

13. Syamenchik, T.A.; Matrenin, S.V. Obtaining prototypes from nanodispersed powders by the method of spark plasma sintering. In Proceedings of the Modern Problems of Mechanical Engineering, the Collection of Scientific Papers of the VII International Scientific and Technical Conference, National Research, Tomsk Polytechnic University, Tomsk, Russian, 11-13 November 2013; Arlyapova, A.Y., Kim, A.B., Eds.; pp. 131-135.

14. Romanov, I.V.; Zadorozhniy, R.N. Choice of modes of electrospark treatment for electrodes from sintered bronze. Sci. Tech. Bull. Bryansk State Univ. 2021, 1, 96-106.

15. Velichko, S.A.; Kravchenko, I.N.; Martynov, A.V.; Martynova, E.G. Formation of thick-layer electrospark coatings with increased contact continuity. STIN 2021, 4, 29-32.

16. Reshchikov, E.O.; Romanov, I.V.; Zadorozhny, R.N. Improving the reliability of friction units made of titanium alloys. Tech. Serv. Mach. 2021, 1, 100-106.

17. Zhachkin, S.Y.; Penkov, N.A.; Sidorkin, O.A.; Zadorozhny, R.N.; Strunkin, P.V. Analytical assessment of wear of the working surface of screw devices with a composite coating. Tech. Serv. Mach. 2021, 2, 151-161. [CrossRef]

18. Velichko, S.A.; Sharifullin, S.N.; Kuznetsov, I.S.; Kolomeichenko, A.V.; Soloviev, R.Y.; Kravchenko, I.N.; Adigamov, N.R. Assessment of wear resistance and resource of hardened by electric spark treatment of cutting surfaces of fingers of grain harvesters headers. In Proceedings of the Innovative Machine-Building Technologies, Proceedings of the Equipment and Materials-2019 Materials of the X International Scientific and Technical Conference, Kazan, Russia, 5-6 December 2019; pp. 191-195.

19. Romanov, I.V.; Zadorozhniy, R.N. Investigation of the physical and mechanical properties of bronze powders obtained by the method of electroerosive dispersion. Tech. Serv. Mach. 2020, 4, 148-156. 